\title{
Effects of nitric oxide on magnocellular neurons of the supraoptic nucleus involve multiple mechanisms
}

\author{
M.P. da Silva*, P.L. Cedraz-Mercez* and W.A. Varanda
}

Departamento de Fisiologia, Faculdade de Medicina de Ribeirão Preto, Universidade de São Paulo, Ribeirão Preto, SP, Brasil

\begin{abstract}
Physiological evidence indicates that the supraoptic nucleus (SON) is an important region for integrating information related to homeostasis of body fluids. Located bilaterally to the optic chiasm, this nucleus is composed of magnocellular neurosecretory cells (MNCs) responsible for the synthesis and release of vasopressin and oxytocin to the neurohypophysis. At the cellular level, the control of vasopressin and oxytocin release is directly linked to the firing frequency of MNCs. In general, we can say that the excitability of these cells can be controlled via two distinct mechanisms: 1) the intrinsic membrane properties of the MNCs themselves and 2) synaptic input from circumventricular organs that contain osmosensitive neurons. It has also been demonstrated that MNCs are sensitive to osmotic stimuli in the physiological range. Therefore, the study of their intrinsic membrane properties became imperative to explain the osmosensitivity of MNCs. In addition to this, the discovery that several neurotransmitters and neuropeptides can modulate their electrical activity greatly increased our knowledge about the role played by the MNCs in fluid homeostasis. In particular, nitric oxide (NO) may be an important player in fluid balance homeostasis, because it has been demonstrated that the enzyme responsible for its production has an increased activity following a hypertonic stimulation of the system. At the cellular level, NO has been shown to change the electrical excitability of MNCs. Therefore, in this review, we focus on some important points concerning nitrergic modulation of the neuroendocrine system, particularly the effects of NO on the SON.
\end{abstract}

Key words: Magnocellular neurons; Supraoptic nucleus; Vasopressin; Oxytocin; Nitric oxide; Homeostasis

\section{Nitric oxide as a messenger molecule}

Studied in 1772 by Joseph Priestly (1), nitric oxide (NO) was taken, at first, to be a toxic gas. However, this view was changed when it was shown that NO was endogenously produced by living organisms. Initially characterized as an endothelium-derived relaxation factor (2), NO was later postulated to be a possible neurotransmitter in the central nervous system by Garthwaite et al. (3). In 1992, NO was named "Molecule of the Year", and its physiological and pharmacological importance became clear through the studies of Louis J. Ignarro, Robert F. Furchgott, and Ferid Murad, who were awarded the Nobel Prize in Physiology or Medicine in 1998 (4). These scientists showed that NO could act as a signaling molecule in the central nervous system, suggesting its role as a neurotransmitter/neuromodulator.
This view changed the classical concepts used to explain communication between neurons, because NO cannot be stored, released, or inactivated by conventional regulatory mechanisms. NO signaling in excitable tissues requires rapid and controlled release to specific cellular targets, since its average lifetime is on the order of a few seconds (5). In principle, NO could spread out from its site of production to influence different types of tissues (neuronal, glial, and vascular) that are not necessarily in anatomical juxtaposition, acting as an autocrine or paracrine signaling molecule. At the present time, there is vast literature focused on the study of the biological effects of NO. This messenger is involved in the function of a great diversity of tissues and is shown to be involved in many different physiological processes. For a review on other aspects of NO function, not addressed in this review, see Calabrese et al. (6).

Correspondence: W.A. Varanda, Departamento de Fisiologia, Faculdade de Medicina de Ribeirão Preto, USP, Av. Bandeirantes, 3900, 14049-900 Ribeirão Preto, SP, Brasil. Fax: +55-16-3630-0017. E-mail: wvaranda@fmrp.usp.br

*These authors contributed equally to this study.

Received July 3, 2013. Accepted October 22, 2013. First published online January 17, 2014. 


\section{Synthesis of NO}

In the organism, NO originates from L-arginine in a process catalyzed by three distinct NO synthase (NOS) enzymes: neuronal NOS (nNOS), endothelial NOS (eNOS), and inducible NOS (iNOS). eNOS and nNOS are constitutively expressed enzymes, which are stimulated by increases in intracellular calcium concentration (7). The immunological functions of NO are mediated by a calcium-independent iNOS that is activated by products released in inflammatory processes such as cytokines, interferon gamma, and interleukins 1 and 2 (8). However, all NOS enzymes use NADPH as an electron donor and require five cofactors as well as the presence of calmodulin to catalyze the oxidation of L-arginine to $\mathrm{NO}$, with a stoichiometric formation of citrulline. The result of this reaction is one molecule of NO plus L-citrulline (9). $\mathrm{L}$-citrulline is recycled back to regenerate L-arginine for a new NO synthesis, closing the cycle of NO production (Figure 1) (10). Since the amount of NADPH and citrulline correspond to the amount of NO produced, they were extensively used as markers of NO production in the brain including the supraoptic nucleus (SON) (11). Nowadays, other approaches can be used to detect NO production with the same precision: for example, fluorescent dyes like DAF and DAF-FM (12), or electrochemical sensors (13).

mRNA transcripts of all NOS isoforms are present in the hypothalamus, with the order of expression being $\mathrm{nNOS}>\mathrm{eNOS}>\mathrm{iNOS}$ (14). In the SON, the main isoform is nNOS (15), and its expression is likely to be controlled in an activity-dependent manner, i.e., increases in activity of the neuron induce an equivalent increase of nNOS in magnocellular neurons (16). However, the effects seen when nNOS is elevated are not completely understood. In the literature, there is a consensus that vasopressinergic

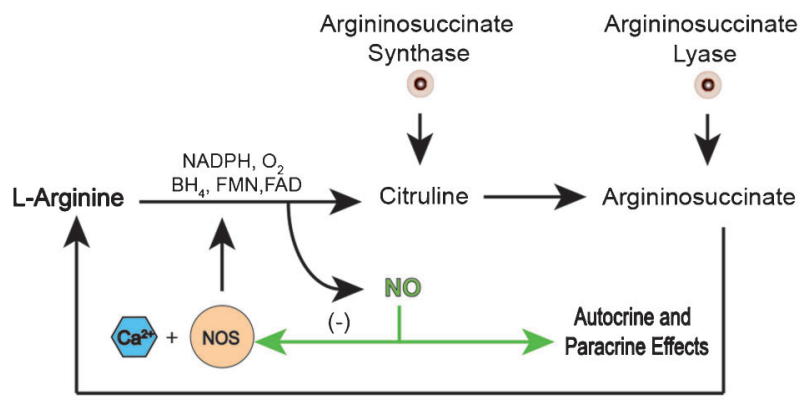

Figure 1. Nitric oxide synthesis. In the presence of NADPH, oxygen and co-factors, such as tetrahydrobiopterin $\left(\mathrm{BH}_{4}\right)$, flavin mononucleotide (FMN), flavin adenine dinucleotide (FAD), nitric oxide (NO) synthase (NOS) plus calcium $\left(\mathrm{Ca}^{2+}\right)$, catalyze the breakdown of L-arginine to citrulline and NO. Citrulline will be recycled back to regenerated L-arginine and NO will produce autocrine and/or paracrine effects as well as negative feedback on NOS. neurons constitute the major neuronal phenotypes expressing nNOS, suggesting a role for this new neurotransmitter in the mechanisms regulating fluid homeostasis (17).

\section{Donors and inhibitors of NO}

To help in the understanding of the biological functions of NO, exogenous sources and inhibitors of this neuromodulator have been developed as research tools. To increase NO levels, both donors and substrates are used. Donors are compounds that release $\mathrm{NO}$, and several compounds have already been described, for example, sodium nitroprusside (SNP), nitroso- $N$-acetylpenicillamine (SNAP), 3-morpholinosydnonimine (SIN-1), and diazeniumdiolates (NONOates).

Chemically, all donors have nitrate functionality within the molecule, and a nitroso functional group is present in all of these compounds (18). Some donors have functional nitrosothiol groups, S-nitrosothiols, whose decomposition is catalyzed by copper ions $\left(\mathrm{Cu}^{+}\right)$to form $\mathrm{NO}$ and disulfide. Interestingly, $S$-nitrosothiols were found endogenously, supposedly acting as NO stores for release when required (19). Another functionally important group is nitrosyl, commonly found in sodium nitroprusside $\left(\mathrm{Na}_{2}\left[\mathrm{Fe}(\mathrm{CN})_{5} \mathrm{NO}\right]-\mathrm{SNP}\right)$, which is a mixed nitrosyl-cyano complex (20). Additionally, other metal complexes have been developed including a nitrosylruthenium complex, which has the advantage of low cytotoxicity and readily releasing NO upon illumination (21). Although the classification of all NO donors is a complicated task, we can say that, when they show similar chemical structures, they usually have similar NOreleasing mechanisms.

SNP was used by several authors in their studies of the SON (22-24). SNP is a complex of ferrous ion with five cyanide anions $\left(\mathrm{CN}^{-}\right)$and a nitrosonium ion $\left(\mathrm{NO}^{+}\right)$. Interaction of SNP with a reducing agent, such as thiols, leads to the formation of NO. Its use in biological systems has the inconvenience that formation of $\mathrm{NO}$ is accompanied by the formation of ferricyanide, a biologically active and toxic compound (25). To avoid the effects of ferricyanide, other types of donors have been used, for example, SNAP, SIN-1, and NONOates. Regarding SNAP, it is a derivative of the nitrosothiol group that seems to provide higher concentrations of $\mathrm{NO}$, but micromolar concentrations of $\mathrm{Cu}^{2+}$ are required for its action (26). SIN-1 also produces $\mathrm{NO}$ and originates a breakdown product, SIN-1C, which is biologically inactive (27). A side effect of SIN-1 is the production of superoxide anion, which can react with $\mathrm{NO}$ and $\mathrm{H}^{+}$to form peroxinitrite $\left(\mathrm{ONOO}^{-}\right)$and hydrogen peroxide $\left(\mathrm{H}_{2} \mathrm{O}_{2}\right)$, both with deleterious effects on membranes (28). NONOates release NO spontaneously in solution at physiological $\mathrm{pH}$ and temperature. The $\mathrm{NO}$ derived from NONOates is not accompanied by the cytotoxic effects of 
hydrogen, alkyl hydroperoxide, or hypoxanthine/xanthine. In addition, other NO donors have been developed, which promise advantages over the previous ones, such as spontaneous release of NO under controlled rates. In the literature, we can find descriptions of a variety of these, i.e., donors with higher levels of NO release without being photosensitive or releasing cyanide: for example, Rut-bpy $\left(\mathrm{Cis}-\left[\mathrm{Ru}(\mathrm{bpy})_{2}\left(\mathrm{SO}_{3}\right)(\mathrm{NO}) \mathrm{PF}_{6}\right)\right.$ (29) and/or donors with protection against hydrogen peroxide-mediated cytotoxicity diethylamine (DEA/NO) and propylamine propylamine (PAPA/NO) (30). The amount and duration of NO release depend on the pharmacological properties of each donor. Thus, some compounds could have a fast action in small quantities or a slow action when NO is released for long periods.

Besides donors, production of endogenous NO can be controlled by using inhibitors of NOS. These inhibitors can be divided into two groups: 1) inhibitors that target cofactor-binding sites and 2) inactive L-arginine analog molecules. The first interfere with flavin, calmodulin, or dioxygen binding sites. These NOS inhibitors have no selectivity for a particular isoform and interfere with the activity of other enzymes that need the same cofactors to become active (31).

In an opposite way, substrates analogous to Larginine have a higher specificity toward the NOS isoforms. These inhibitors act as false substrates by binding to the L-arginine binding site (32). Although over one-hundred NOS inhibitors have been described as possible pharmacological tools (31) reducing or preventing the biological effects of $\mathrm{NO}(2,5)$, the majority of them are nonselective, and just a few compounds, such as 7-nitro-indazole, amidines, and some amino acid derivatives, are able to selectively inhibit nNOS $(33,34)$. $\mathrm{N}^{\omega}$-nitro-L-arginine methyl ester (L-NAME), a nonselective NOS inhibitor, has been extensively used in studies of the $\operatorname{SON}(23,35,36)$.

\section{Mechanisms of action}

\section{Guanylate cyclase}

Although the number of newly discovered potential targets of NO increases continually, its major effect, under physiological conditions, appears to be mediated mainly through the activation of soluble guanylate cyclase (sGC), the intracellular NO receptor. SGC is a heterodimer composed of $\alpha$ - and $\beta$-subunits. Due to the electronic structure of NO, an uncharged molecule, it activates SGC by binding directly to the heme portion, leading to a conformational change that augments enzyme activity by forming a ferrous-nitrosyl-heme complex. At this point, there is conversion of GTP to cGMP followed by intracellular activation of several effectors (37). Some of the effectors were identified as 1) cGMP-dependent protein kinase, 2) cGMP-regulated phosphodiesterases, and 3) cGMP-gated ion channels (38). Although it seems that the effects of NO are cGMP dependent, in the SON the evidence is controversial. Yang and Hatton (23) have shown that cGMP enhances dye coupling and excitability of supraoptic neurons. On the other hand, studies have shown that nitrergic modulation of magnocellular neurons of the SON involves an increase in the frequency of $\gamma$-aminobutyrate (GABA)ergic events (24) and that the signal transduction is independent of cGMP (39). The same type of result was observed in the neurosecretion of vasopressin (VP) and oxytocin (OT) in experiments with awake rats (39). In brain slices of the SON, using the outside-out configuration of the patch-clamp technique, results show that $\mathrm{NO}$ acts directly on the N-methyl-Daspartate receptor (NMDA) channel complex, without mobilization of cGMP (40). However, to make the subject more complicated, our group has demonstrated that nitrergic modulation can be independent of synaptic events, suggesting a possible direct action on ion channels (35). As can be seen, the pathway used by $\mathrm{NO}$ to change the excitability of magnocellular neurons is still a matter of debate.

\section{An alternative pathway}

The classical view of cGMP being the exclusive mediator of the effects of NO has been questioned by findings suggesting that NO can modify proteins through direct chemical reactions (41). One of those alternative pathways involves S-nitrosylation, in which the NO molecule interacts with cysteine thiol groups in a covalent bond, resulting in an S-nitrosothiol complex (Figure 2). This mechanism has been described as an important NO reaction, which preserves its biological actions, and can be expressed as a key posttranslational modification of ion channels increasing or decreasing protein activity $(42,43)$. Thus, protein functions can be controlled by either interaction or deletion of NO from the cysteine thiol group. For more details about S-nitrosylation, see Hess et al. (42).

In the central nervous system, this process was first described in NMDA-type glutamate receptors, where the cysteine (residue 399) in the NR2A subunit was nitrosylated (44). However, emerging results have demonstrated

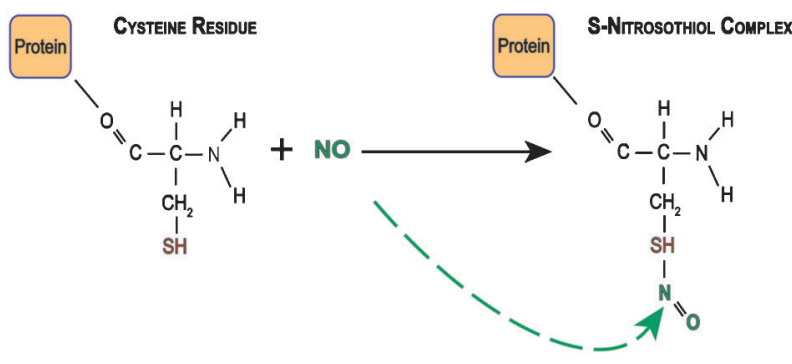

Figure 2. S-nitrosylation at cysteine residues. After synthesis, nitric oxide (NO) reacts with cysteine residues (red) of proteins forming a nitrosylated compound. 
that other proteins can also be nitrosylated, such as, calcium-activated potassium channels (45), cyclic nucleotide activated cation channels (46), and hyperpolarizing activated and cyclic nucleotide gated cation channels (47). In addition, Jaffrey et al. (48) verified that some proteins are endogenously nitrosylated, reinforcing the idea that this signaling mechanism for $\mathrm{NO}$ is of physiological significance.

\section{NO effects on the mammalian SON}

The observation that osmotic stimulation upregulated NOS as well as VP and OT mRNA expression in magnocellular neurosecretory cells (MNCs) of the SON was taken as evidence that NO could play a role as a neuromessenger involved in the control of neurohypophysial hormone secretion (16). Additional immunohistochemical evidence colocalizing NOS with VP or OT and detection of NOS mRNA, NOS protein, and its product L-citrulline in MNCs lends further support to this idea. Moreover, in vivo and in vitro studies also produced a wealth of results that revealed a significant participation of $\mathrm{NO}$ in the control of VP and OT secretions $(49,50)$.

Through a dynamic approach using confocal microscopy and NO-sensitive indicators, a basal production of $\mathrm{NO}$ at the cellular level was detected within the SON, but not the surrounding nuclei (51). Moreover, hyperosmotic stimulation induced $\mathrm{NO}$ production in MNCs in slices of the SON (52). This finding adds support to the hypothesis that osmotic stimulation induces an increase in NO production as a consequence of NOS overexpression $(16,53)$

\section{Controversial effects of NO on VP and OT secretion}

Results concerning the central effects of NO on VP and OT plasma levels are not always coincident and are sometimes contradictory. Table 1 shows a collection of the main findings from experiments using intracerebroventricular (icv) injections of $\mathrm{NO}$ donors, L-arginine, or NOS blockers (L-NAME). Under physiological conditions, icv injection of L-NAME elicits an increase in both VP and OT plasma levels (54). This result indicates that NO tonically inhibits neurohormonal secretion. On the other hand, increased or unmodified effects on plasma VP levels were shown after icv injections of $\mathrm{NO}$ donors and L-arginine treatment (54-56).

Since increased plasma levels of VP and OT were observed after blockade of endogenous NO production, it would be expected that increased $\mathrm{NO}$ availability, after treatment with NO donors or L-arginine, would induce opposite effects. However, similar to the blocking of endogenous NO production, a larger NO availability also increased VP and OT plasma levels. On the contrary, in vitro studies reveal different effects of NO on neurohypophysial hormone secretion. In rodent hypothalamic explants, NO suppressed VP secretion, an effect seen with NO donors SIN-1 and SNP $(49,57)$. L-arginine also reduced VP release in this preparation, an effect reversed and reduced, respectively, by the NOS blocker L-NMMA and the addition of human hemoglobin, an NO scavenger (49). In microinjection experiments, interpretation of the results needs to take into consideration the microenvironments of the nuclei. Different brain nuclei have different sizes and can be damaged by microinjections with relatively large volumes. In situations like this, the effects observed are subjected to severe criticism because of the possibility of mechanical lesions and tissue edema. Furthermore, nuclei in the surroundings of the injection site can also be affected by the injected drug, and the final measured response may be misleading (58). A third and very important point is the concentration of drug used. As can be seen in Table 1, icv microinjections of donor and

Table 1. The hypothalamic-neurohypophyseal axis is modulated by the central nitrergic system.

\begin{tabular}{|c|c|c|c|c|c|}
\hline \multirow[t]{2}{*}{ icv treatment } & \multirow{2}{*}{$\begin{array}{l}\text { Drug concentration } \\
(\mu \mathrm{g} / \mu \mathrm{L})\end{array}$} & \multirow{2}{*}{$\begin{array}{c}\text { Volume } \\
\text { microinjected }(\mu \mathrm{L})\end{array}$} & \multicolumn{2}{|c|}{ Hormone } & \multirow[t]{2}{*}{ Reference } \\
\hline & & & VP & ОТ & \\
\hline \multirow[t]{2}{*}{ No donor (SNAP) } & 1.25 and 2.5 & 10 & $\uparrow$ & NR & Ota et al. (56) \\
\hline & 1 & 5 & NS & NS & Reis et al. (86) \\
\hline \multirow[t]{3}{*}{ L-arginine } & 50 and 100 & 10 & $\uparrow$ & NR & Ota et al. (56) \\
\hline & 100 & 10 & $\uparrow$ & NR & Cao et al. (87) \\
\hline & 40 & 0.5 & NS & NS & Reis et al. (54) \\
\hline \multirow[t]{3}{*}{ NOS blocker (L-NAME) } & 54 & 5 & $\downarrow$ & NR & Cao et al. (87) \\
\hline & 50 & 5 & $\uparrow$ & $\uparrow$ & Kadekaro et al. (88) \\
\hline & 80 & 0.5 & $\uparrow$ & $\uparrow$ & Reis et al. (54) \\
\hline
\end{tabular}

Plasma vasopressin (VP) and oxytocin (OT) levels from euhydrated rats treated with icv injections of NO donors, L-arginine or nitric oxide synthase (NOS) blocker. Upward and downward arrows indicate significant enhanced and reduced plasma levels when compared with the control group, respectively. SNAP: S-nitroso-N-acetylpenicillamine; L-NAME: $\mathrm{N}^{\omega}$-nitro-L-arginine methyl ester. NS: nonsignificant changes compared to the control group; NR: non-reported information. 
substrate of $\mathrm{NO}$ resulted, at the higher doses, in an increase in the release of VP. Such an effect is opposite to that observed in in vitro studies, where the release of VP was inhibited. However, in experiments where the NOS enzyme was blocked, the results obtained with microinjections are more similar to those obtained from in vitro experiments. Thus, although results from in vivo studies are controversial, findings from in vitro studies are more consistent, indicating a general inhibitory effect of $\mathrm{NO}$ on neurohypophysial hormone secretion. On the other hand, in dehydrated rats icv microinjections of L-NAME, an NOS blocker, induced an acute increase in OT, but not VP plasma levels, suggesting that the postulated tonic nitrergic inhibition of VP secretion is removed during dehydration (59). Such an effect was also reported after icv injection of angiotensin II (Angll), hypertonic solution treatment (60), and in hypovolemic rats (36). Besides this, NO seems to induce an increase in VP, but not in OT plasma levels induced by hypertonic blood volume expansion (61). Taken together, these findings indicate that, similar to what happens during hypovolemia, total and intracellular dehydration removes tonic inhibitory nitrergic modulation on VP neurons, but not on OT neurons. Therefore, it seems that nitrergic modulation on the hypothalamic-neurohypophysis axis can be strongly controlled by reflex responses activated by osmotic imbalance and depletion of body fluid compartments.

From the above discussions, the question that remains is: How could osmotic and volume challenges induce such diverse nitrergic effects on VP and OT secretions? It is known that dehydration and salt load induce overexpression of neuronal NOS mRNA in MNCs $(53,62)$, a response controlled by the anteroventral third ventricular (AV3V) region (63). Thus, it is expected that 24-h dehydration would increase the levels of NO into the SON, with a consequent inhibition of VP and OT secretion. In order to address this problem, we should recall that hypovolemia, hypotension, and total dehydration, but not intracellular dehydration, significantly increase in Angll plasma levels. Circulating Angll may induce VP (64) and OT (65) secretion by acting on circumventricular organ neurons, where the blood-brain barrier is absent (66). Thus, circulating Angll may activate neurons at the subfornical organ (67), which sends axonal projections to the SON, increasing MNC activity via Angll release and activation of postsynaptic Angll receptors type-1 (AT1). This hypothesis is supported by experiments showing that administration of AT1 receptor antagonist suppresses the Angll response (68). Similarly, cellular dehydration induced by hypertonic solution activates subfornical organ neurons enhancing Angll transmission to MNCs (64). How can a blood-borne signal like Angll modulate the nitrergic system present in the SON? Experimental evidence shows that Angll could modulate nNOS mRNA expression in MNCs (69). Such modulation is dependent on nNOS activity itself, since its blockade prevented Angll-induced nNOS mRNA overexpression in the SON. Therefore, we can assume that Angll receptor (AT) activation modulates the nitrergic system in MNCs. In neurons, increased NO production as a consequence of the AT1 receptor antagonist, losartan, is a response that may be blocked by an AT2 receptor antagonist, such as PC123319 (70). This indicates that, while Angll binding to AT1 receptors inhibits tonically produced NO, binding to AT2 receptors stimulates it. In this case, NO production was exclusively dependent on nNOS (70). How could the modulation of activity of Angll receptors explain selective nitrergic inhibition on OT secretion? According to Wang et al. (70), since Angll receptor activation stimulates or inhibits NO production, the balance between AT1 and AT2 activities may be decisive for VP and OT release. However, during dehydration, icv microinjection of losartan did not induce any changes in VP and OT plasma levels. On the other hand, icv losartan plus icv L-NAME elicited increased OT secretion. It is likely that, in MNCs, enhanced NO production is the consequence of both neuronal NOS stimulation via AT2 receptor activation and reduction of NOS inhibition via AT1 inactivation by losartan. Therefore, it seems that, when AT1 receptors are inactivated, Angll activates AT2 receptors in MNCs, eliciting overactivity of NOS, increased NO production, and inhibition of VP and OT secretion. Such a hypothesis would explain the increased OT plasma levels after icv L-NAME treatment, but would not explain nonsignificant changes on VP secretion. We could speculate that AT2 receptors are absent in VP neurons, but they have been detected in rodent VP neurons (71). Thus, to this point, we may assume that Angll may induce NO production through AT2 receptors, via nNOS activation, with consequent inhibition of both VP and OT secretion. However, another question remains: Why is OT, and not VP secretion, affected by L-NAME treatment? A possible explanation emerges from studies involving stimulation of AT2 receptors and consequent production of phospholipase A2 and arachidonic acid (72). Arachidonic acid is the substrate for cyclooxygenase enzymes (COX-1 and COX2) to produce prostaglandins ( $P G s$ ), also involved in the control of neurohypophysial hormone secretion. Indeed, central microinjections of different types of PGs elicit VP and OT secretion $(73,74)$, an effect also observed in in vitro preparations (75). Interestingly, Yamaguchi et al. $(73,74)$ observed that, in rats, brain PGs were synthesized during hyperosmolarity and volume depletion, but not under physiological conditions, suggesting that $\mathrm{COX}$ enzymes are activated by osmotic stress and hypovolemia. This is a plausible assumption, since COX-2 is also a constitutively expressed enzyme in the brain (76), lending support to the hypothesis that PGs participate in selective nitrergic inhibition on OT secretion during dehydration. Since NO can directly activate COXs $(77,78)$, we 
speculate that dehydration-induced NOS overexpression (79) would lead to an enhanced activation of the COX enzymes and synthesis of PGs, thereby inducing neurohypophysial hormone secretion. Central microinjection of meclofenamate, a COX inhibitor, increased VP plasma levels during osmotic stimulation and hypovolemia, an effect not observed in euvolemic and euhydrated rats. Such results indicate that osmotic and volume imbalances stimulate central synthesis of PGs, which tonically induce the secretion of VP $(73,74)$. Interestingly, it was reported that icv microinjections of PGE2 or PGF2 $\alpha$ elicit OT, but not VP secretion (77). The activation of SON neurons by PGE2 occurs via binding to prostanoid receptors. In the SON, electrophysiological investigations showed that PGE2 increases neuronal activity through postsynaptic PGE2 and PGF2 $\alpha$ receptors. Indirectly, PGE2 induces MNC activation by reducing the inhibitory GABA inputs via presynaptic EP3 receptors (80). Thus, we may speculate that, during dehydration, NO and PGs are two immediately synthesized factors with opposing effects to control MNC activity and neurohormonal secretion. As NO may induce additional synthesis of PGs through direct effects on COX, PG levels may increase during dehydration in parallel with NO production. The counterbalance between both factors maintains OT and VP secretions at optimal levels. Even when icv L-NAME treatment interrupts NO production, COX enzymes $S$-nitrosylated by NO may maintain the PG levels. In addition, the high sensitivity of OT neurons to PGE2 and PGF2 $\alpha$ may explain the exclusive increase in OT plasma levels after L-NAME treatment (77), since icv indomethacin microinjection suppressed L-NAME-induced OT secretion and did not change VP levels (81).

In summary, although in vivo experiments brought relevant contributions to understanding the control of neuroendocrine function by the brain nitrergic system, in vitro studies were also needed to unveil the nitrergic mechanisms controlling VP and OT secretion. In this regard it is worth noting that, although in vivo studies suggest that the activity of MNCs is modulated by synaptic neurotransmission, it is also well known that NO plays an important modulator effect by controlling their activity through both indirect (synaptic) and direct (intrinsic) mechanisms.

\section{Indirect effects of NO on MNCs: synaptic mechanism}

In vitro electrophysiological experiments were necessary to understand how NO induces changes in VP and OT plasma levels. Since release of VP and OT is correlated with the electrical activity of MNCs, several papers have investigated the effects of $\mathrm{NO}$ on the pattern and frequency of firing neurons of action potentials. To investigate how the effect of $\mathrm{NO}$ inhibits electrical activity of SON neurons, spontaneous excitatory (EPSCs) and inhibitory (IPSCs) postsynaptic currents were recorded using the whole cell patch-clamp technique in unidentified SON neurons (82). NO reversibly increased only the frequency of IPSCs and did not change the amplitudes of either IPSCs or EPSCs. Since both IPSCs and EPSCs were recorded in the presence of tetrodotoxin, the spontaneous synaptic currents are, in fact, miniature IPSCs and EPSCs representing local release of GABA and glutamate, respectively (83). Contrary to the above results, it was reported that SNP, a donor of $\mathrm{NO}$, and $\mathrm{L}$-arginine, precursor of NO synthesis, increase both the frequency and amplitude of $\mathrm{GABA}_{\mathrm{A}}$ miniature IPSCs in VP and OT neurons (24). This finding was taken to indicate that NO modulates GABA neurotransmission at both pre- and postsynaptic sites. Such evidence lends support to the idea that NO increases the presynaptic quantal release of GABA and the open probability $\left(P_{0}\right)$ of $\mathrm{GABA}_{\mathrm{A}}$ channels, since IPSC currents were abolished by the $\mathrm{GABA}_{\mathrm{A}}$ channel blocker, picrotoxin (82). Although controversy still remains about a possible postsynaptic effect, the increase in amplitude elicited by L-arginine and the reversal of this effect by the nNOS inhibitor, 7-nitroindazole, suggest that postsynaptic GABA channel activity may be influenced by endogenous NO (24). Also, the NO donor, SNP, is known to negatively modulate glutamatergic neurotransmission in SON neurons (22). However, such evidence must be considered with caution, because it is well known that ferrocyanide ions, a byproduct of SNP photolysis, mimicked the effects of SNP on NMDA currents in neurons (25). Although Ozaki et al. (82) did not observe any effect of SNAP (NO donor) on the spontaneous EPSCs in SON neurons, there are reports that NMDA currents in striatal neurons are negatively modulated by other NO donors (27). In summary, endogenous NO acts indirectly on MNCs by enhancing fast inhibitory synaptic transmission through the induction of presynaptic GABA release, as well as by modulating the conductance and/or $P_{0}$ of postsynaptic $\mathrm{GABA}_{\mathrm{A}}$ channels.

\section{Direct effects of NO on MNCs: intrinsic mechanisms}

NO may also inhibit the electrical activity of MNCs by acting independently of inhibitory synaptic input. Such a hypothesis has arisen from experiments where the effects of NO were observed in the presence of blockers of both GABAergic and glutamatergic neurotransmissions. Under these conditions, treatment of MNCs with L-arginine reduced their firing rate while treatment with L-NAME, an NOS blocker, produced the opposite effect. These observations are clear indications that endogenous NO directly inhibits the electrical activity of MNCs, independently of an effect via GABAergic neurotransmission. A more detailed analysis of the phenomenon showed that NO promotes a slower depolarization by increasing the 


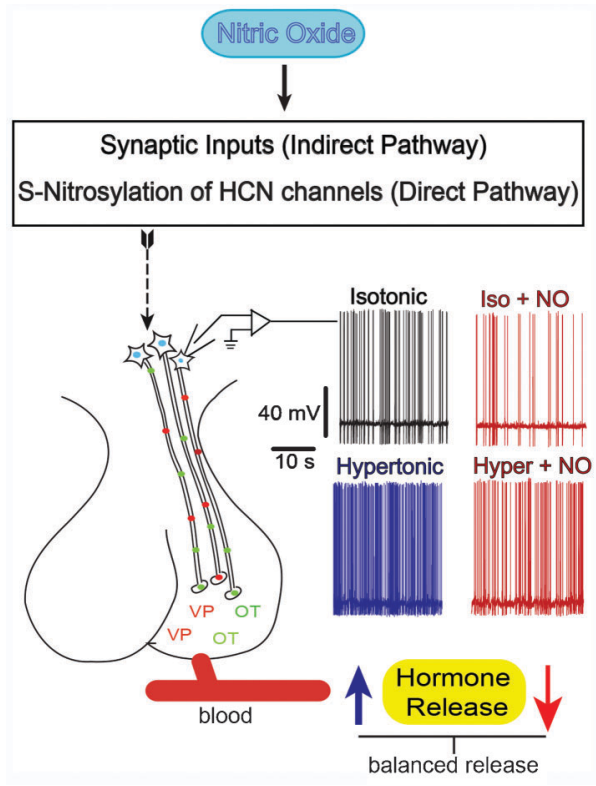

Figure 3. Direct and indirect mechanisms involved in the control of magnocellular neurosecretory cells (MNCs) firing frequency by nitric oxide (NO). NO controls the firing rate of the MNCs in order to prevent over-secretion of the neurohypophysial hormones through an indirect (increase in synaptic inputs) and/or a direct pathway by S-nitrosylation of hyperpolarization-activated and cyclic nucleotide-gated (HCN) channels (see text). Traces shown on each side of the neurohypophysis are action potentials recorded directly from the MNCs under the conditions indicated. Increased firing rate (blue trace), induced by a hypertonic solution, is associated with an increased VP/OT secretion (blue arrow). NO decreases firing rates (red traces) in both basal and osmotic stress conditions. Voltage and time scales are the same for all records.

hyperpolarizing after potential amplitude (35), a component involved with spike frequency adaptation. Depolarization after potentials are determined by inward cation currents flowing through, but not only, hyperpolarization-activated and cyclic nucleotide-gated channels (HCN channels). Current flowing through the HCN channels $\left(I_{h}\right)$ is involved in the control of neuronal rhythmic activity, also regulating the spontaneous activity of MNCs. It has been observed in our lab that NO decreases the amplitude of $I_{h}$ currents. This effect on the $\mathrm{HCN}$ channels seems to be independent of the soluble guanylyl cyclase-cGMP pathway (da Silva MP and Varanda WA, unpublished results), since the soluble guanylyl cyclase inhibitor, $1 \mathrm{H}-[1,2,4]$ oxadiazolo[4,3-a] quinoxalin-1-one (ODQ), did not prevent the effects of Larginine. Alternative routes by which $\mathrm{NO}$ may modulate the kinetics of HCN channels may involve other intracellular messenger pathways (84) and/or the S-nitrosylation mechanism proposed to occur in other cell types.

\section{Hyperosmolality and NO signaling in MNCs}

Nitrergic signaling in MNCs seems also to be influenced by osmosensitive mechanisms. Blockade of NOS depolarizes the resting membrane potential both in hyperosmotic and isotonic conditions. Indeed, L-arginine significantly decreased the action potential firing rate elicited by hypertonicity, and blocking NOS induced a further increase in the frequency of action potential firing induced by the hypertonic solution. This suggests that, during the osmotic challenge, endogenous NO is synthesized, and modulates the electrical activity of MNCs (52).

Since these results were obtained without major excitatory and inhibitory synaptic input, they suggest that MNCs exhibit intrinsic osmosensitivity, which may induce the synthesis of NO. How do intrinsic osmosensitive mechanisms affect nitrergic signaling in MNCs? A cationic conductance is augmented in MNCs during hyperosmotic stress, suggesting that intrinsic osmosensitivity may directly modulate the synthesis of NO. Recently, it was reported that an $\mathrm{N}$-terminal variant of the transient receptor potential cation channel subfamily $\mathrm{V}$ member 1 (TRPV1) is essential for osmosensory transduction in supraoptic MNCs. A splice variant of the TRPV1 channel mediated hyperosmotic stimulus-induced depolarizing potential and action potential discharge (85). As the activation of TRPV channels is known to occur during

Table 2. Brain nitrergic system differentially modulates vasopressin (VP) and oxytocin (OT) secretion in rats under osmotic or volume challenge.

\begin{tabular}{|c|c|c|c|c|c|c|c|c|c|c|}
\hline & \multicolumn{2}{|c|}{$\begin{array}{l}\text { Physiological } \\
\text { conditions }\end{array}$} & \multicolumn{2}{|c|}{$\begin{array}{l}\text { Microinjection } \\
\text { of Angll }\end{array}$} & \multicolumn{2}{|c|}{$\begin{array}{c}\text { Total } \\
\text { dehydration }\end{array}$} & \multicolumn{2}{|c|}{$\begin{array}{l}\text { Intracellular } \\
\text { dehydration }\end{array}$} & \multicolumn{2}{|c|}{ Hypovolemia } \\
\hline & VP & OT & VP & OT & VP & OT & VP & OT & VP & OT \\
\hline $\begin{array}{l}\text { Effect of central } \\
\text { NOS blockade }\end{array}$ & $\uparrow$ & $\uparrow$ & NS & $\uparrow$ & NS & $\uparrow$ & NS & $\uparrow$ & NS & $\uparrow$ \\
\hline
\end{tabular}

Brain nitrergic system was blocked by icv microinjection of L-NAME $(50 \mu \mathrm{g} / \mu \mathrm{L})$. Under physiological conditions, central nitric oxide synthase (NOS) blockade negatively modulates VP and OT secretion. On the other hand, icv microinjection of Angll (50 ng/ $\mu \mathrm{L})$, total (intracellular + extracellular) and intracellular dehydrations and hypovolemia remove the inhibitory effect on VP secretion and kept the inhibitory effects only on OT secretion. Upward arrows indicate significant increase compared to the control group. NS: nonsignificant changes compared to the control group. Data obtained from Refs. 33, 49, 55, and 56. 
hypertonicity and may lead to NO synthesis, it is suggested that an osmotic stimulus may also indirectly elicit NO synthesis in MNCs through this pathway.

\section{Concluding remarks}

Although NO is a gas, its diffusion radius limits the extension of its actions. Thus, it is thought that endogenous NO produced within the SON represents an important neuromessenger to quickly control the activity of MNCs acting at synaptic elements and/or the MNCs themselves. NO may be seen as a fine tuner modulating MNC activity by increasing GABA neurotransmission and reducing $I_{h}$ currents. In this way, $N O$ is part of a feedback compensatory mechanism that is set to avoid overactivity

\section{References}

1. Ignarro LJ. Biosynthesis and metabolism of endotheliumderived nitric oxide. Annu Rev Pharmacol Toxicol 1990; 30: 535-560, doi: 10.1146/annurev.pa.30.040190.002535.

2. Palmer RM, Ferrige AG, Moncada S. Nitric oxide release accounts for the biological activity of endothelium-derived relaxing factor. Nature 1987; 327: 524-526, doi: 10.1038/ $327524 a 0$

3. Garthwaite J, Charles SL, Chess-Williams R. Endotheliumderived relaxing factor release on activation of NMDA receptors suggests role as intercellular messenger in the brain. Nature 1988; 336: 385-388, doi: 10.1038/336385a0.

4. Derentowicz P, Markiewicz K, Wawrzyniak M, CzerwinskaKartowicz I, Bulawa E, Siwinska-Golebiowska H. [Nitric oxide (NO) - Nobel prize in medicine and physiology for 1998]. Med Wieku Rozwoj 2000; 4: 209-217.

5. Santos RM, Lourenco CF, Ledo A, Barbosa RM, Laranjinha $\mathrm{J}$. Nitric oxide inactivation mechanisms in the brain: role in bioenergetics and neurodegeneration. Int J Cell Biol 2012; 2012: 391914, doi: 10.1155/2012/391914.

6. Calabrese V, Mancuso C, Calvani M, Rizzarelli E, Butterfield DA, Stella AM. Nitric oxide in the central nervous system: neuroprotection versus neurotoxicity. Nat Rev Neurosci 2007; 8: 766-775, doi: 10.1038/nrn2214.

7. Moncada S, Palmer RM, Higgs EA. Nitric oxide: physiology, pathophysiology, and pharmacology. Pharmacol Rev 1991; 43: 109-142.

8. Kleinert H, Pautz A, Linker K, Schwarz PM. Regulation of the expression of inducible nitric oxide synthase. Eur $J$ Pharmacol 2004; 500: 255-266, doi: 10.1016/j.ejphar.2004. 07.030 .

9. Groves JT, Wang CC. Nitric oxide synthase: models and mechanisms. Curr Opin Chem Biol 2000; 4: 687-695, doi: 10.1016/S1367-5931(00)00146-0.

10. Bush PA, Gonzalez NE, Griscavage JM, Ignarro LJ. Nitric oxide synthase from cerebellum catalyzes the formation of equimolar quantities of nitric oxide and citrulline from Larginine. Biochem Biophys Res Commun 1992; 185: 960966, doi: 10.1016/0006-291X(92)91720-B.

11. Miyagawa $A$, Okamura $H$, Ibata $Y$. Coexistence of oxytocin and $\mathrm{NADPH}$-diaphorase in magnocellular neurons of the paraventricular and the supraoptic nuclei of the rat hypothalamus. of MNCs and, hence, oversecretion of VP and OT. Osmotic stress increases NO levels in MNCs, indirectly through glutamatergic neurotransmission and, directly, possibly through TRPV activation. Increased NO levels would avoid excessive MNC activation, and hence VP and OT depletion. Figure 3 and Table 2 depict the relevant points involved in the control of VP and OT secretion as described earlier.

\section{Acknowledgments}

Research supported by FAPESP (\#2012/19750-7) to W.A. Varanda. M.P. da Silva is the recipient of a fellowship from CAPES (Proex \#23038.006588/201144) and P.L. Cedraz-Mercez from FAPESP (\#2012/ 01859-2). W.A. Varanda is a research fellow from CNPq.

Neurosci Lett 1994; 171: 13-16, doi: 10.1016/0304-3940(94) 90592-4.

12. Kojima H, Urano $Y$, Kikuchi $K$, Higuchi T, Hirata $Y$, Nagano T. Fluorescent Indicators for Imaging Nitric Oxide Production. Angew Chem Int Ed Engl 1999; 38: 32093212, doi: 10.1002/(SICl)1521-3773(19991102)38:21 $<3209$ ::AID-ANIE3209>3.0.CO;2-6.

13. Malinski T, Mesaros S, Tomboulian P. Nitric oxide measurement using electrochemical methods. Methods Enzymol 1996; 268: 58-69, doi: 10.1016/S0076-6879(96) 68009-4.

14. Bhat G, Mahesh VB, Aguan K, Brann DW. Evidence that brain nitric oxide synthase is the major nitric oxide synthase isoform in the hypothalamus of the adult female rat and that nitric oxide potently regulates hypothalamic cGMP levels. Neuroendocrinology 1996; 64: 93-102, doi: 10.1159/000 127104.

15. Vincent SR, Kimura $\mathrm{H}$. Histochemical mapping of nitric oxide synthase in the rat brain. Neuroscience 1992; 46: 755784, doi: 10.1016/0306-4522(92)90184-4.

16. Kadowaki K, Kishimoto J, Leng G, Emson PC. Upregulation of nitric oxide synthase (NOS) gene expression together with NOS activity in the rat hypothalamo-hypophysial system after chronic salt loading: evidence of a neuromodulatory role of nitric oxide in arginine vasopressin and oxytocin secretion. Endocrinology 1994; 134: 1011-1017, doi: 10.1210/en.134.3.1011.

17. Calka J, Block $\mathrm{CH}$. Relationship of vasopressin with NADPH-diaphorase in the hypothalamo-neurohypophysial system. Brain Res Bull 1993; 32: 207-210, doi: 10.1016/ 0361-9230(93)90177-D.

18. Yamamoto T, Bing RJ. Nitric oxide donors. Proc Soc Exp Biol Med 2000; 225: 200-206, doi: 10.1046/j.1525-1373. 2000.22525.x.

19. Al-Sa'doni H, Ferro A. S-Nitrosothiols: a class of nitric oxidedonor drugs. Clin Sci 2000; 98: 507-520, doi: 10.1042/ CS19990267.

20. Wang PG, Xian M, Tang X, Wu X, Wen Z, Cai T, et al. Nitric oxide donors: chemical activities and biological applications. Chem Rev 2002; 102: 1091-1134, doi: 10.1021/cr000040I.

21. Lunardi CN, da Silva RS, Bendhack LM. New nitric oxide 
donors based on ruthenium complexes. Braz J Med Biol Res 2009; 42: 87-93, doi: 10.1590/S0100-879X2009000 100013.

22. Cui LN, Inenaga K, Nagatomo T, Yamashita H. Sodium nitroprusside modulates NMDA response in the rat supraoptic neurons in vitro. Brain Res Bull 1994; 35: 253-260, doi: 10.1016/0361-9230(94)90131-7.

23. Yang QZ, Hatton GI. Nitric oxide via cGMP-dependent mechanisms increases dye coupling and excitability of rat supraoptic nucleus neurons. J Neurosci 1999; 19: 42704279.

24. Stern JE, Ludwig M. NO inhibits supraoptic oxytocin and vasopressin neurons via activation of GABAergic synaptic inputs. Am J Physiol Regul Integr Comp Physiol 2001; 280: R1815-R1822.

25. Manzoni O, Prezeau L, Desagher S, Sahuquet A, Sladeczek F, Bockaert J, et al. Sodium nitroprusside blocks NMDA receptors via formation of ferrocyanide ions. Neuroreport 1992; 3: 77-80, doi: 10.1097/00001756199201000-00020.

26. Dicks AP, Williams DL. Generation of nitric oxide from S-nitrosothiols using protein-bound $\mathrm{Cu}^{2+}$ sources. Chem Biol 1996; 3: 655-659, doi: 10.1016/S1074-5521(96)90133-7.

27. Manzoni O, Prezeau L, Marin P, Deshager S, Bockaert J, Fagni L. Nitric oxide-induced blockade of NMDA receptors. Neuron 1992; 8: 653-662, doi: 10.1016/0896-6273(92) 90087-T.

28. Feelisch M. The use of nitric oxide donors in pharmacological studies. Naunyn Schmiedebergs Arch Pharmacol 1998; 358: 113-122, doi: 10.1007/PL00005231.

29. Campelo MW, Campelo AP, Lopes LG, Santos AA, Guimaraes SB, Vasconcelos PR. Effects of Rut-bpy (Cis-[Ru(bpy)2(SO3)(NO)]PF 6), a novel nitric oxide donor, in L-NAME-induced hypertension in rats. Acta Cir Bras 2011; 26 (Suppl 1): 57-59, doi: 10.1590/S0102-86502011000700012.

30. Wink DA, Cook JA, Pacelli R, Liebmann J, Krishna MC, Mitchell JB. Nitric oxide (NO) protects against cellular damage by reactive oxygen species. Toxicol Lett 1995; 82-83: 221-226, doi: 10.1016/0378-4274(95)03557-5.

31. Moore PK, Handy RL. Selective inhibitors of neuronal nitric oxide synthase - is no NOS really good NOS for the nervous system? Trends Pharmacol Sci 1997; 18: 204-211.

32. Bryk R, Wolff DJ. Pharmacological modulation of nitric oxide synthesis by mechanism-based inactivators and related inhibitors. Pharmacol Ther 1999; 84: 157-178, doi: 10.1016/ S0163-7258(99)00030-3.

33. Moore PK, Babbedge RC, Wallace P, Gaffen ZA, Hart SL. 7-Nitro indazole, an inhibitor of nitric oxide synthase, exhibits anti-nociceptive activity in the mouse without increasing blood pressure. $\mathrm{Br} J$ Pharmacol 1993; 108: 296-297, doi: 10.1111/j.1476-5381.1993.tb12798.x.

34. Huang $H$, Martasek P, Roman LJ, Masters BS, Silverman RB. N(omega)-Nitroarginine-containing dipeptide amides. Potent and highly selective inhibitors of neuronal nitric oxide synthase. J Med Chem 1999; 42: 3147-3153, doi: 10.1021/ jm990111c.

35. Ventura RR, Aguiar JF, Antunes-Rodrigues J, Varanda WA. Nitric oxide modulates the firing rate of the rat supraoptic magnocellular neurons. Neuroscience 2008; 155: 359-365, doi: 10.1016/j.neuroscience.2008.06.005.

36. Kadekaro M, Terrell ML, Liu H, Gestl S, Bui V, Summy-Long
JY. Effects of L-NAME on cerebral metabolic, vasopressin, oxytocin, and blood pressure responses in hemorrhaged rats. Am J Physiol 1998; 274: R1070-R1077.

37. Waldman SA, Murad F. Cyclic GMP synthesis and function. Pharmacol Rev 1987; 39: 163-196.

38. Vaandrager AB, de Jonge HR. Signalling by cGMP-dependent protein kinases. Mol Cell Biochem 1996; 157: 23-30.

39. Terrell ML, Salas N, Bui V, Summy-Long JY, Kadekaro M. NO inhibition of the magnocellular neuroendocrine system in rats is independent of cGMP signaling pathway. Exp Neurol 2003; 184: 846-856, doi: 10.1016/S0014-4886(03) 00305-4.

40. Fagni L, Olivier M, Lafon-Cazal M, Bockaert J. Involvement of divalent ions in the nitric oxide-induced blockade of $\mathrm{N}$-methyl-D-aspartate receptors in cerebellar granule cells. Mol Pharmacol 1995; 47: 1239-1247.

41. Ahern GP, Klyachko VA, Jackson MB. cGMP and S-nitrosylation: two routes for modulation of neuronal excitability by NO. Trends Neurosci 2002; 25: 510-517, doi: 10.1016/S0166-2236(02)02254-3.

42. Hess DT, Matsumoto A, Kim SO, Marshall HE, Stamler JS. Protein S-nitrosylation: purview and parameters. Nat Rev Mol Cell Biol 2005; 6: 150-166, doi: 10.1038/nrm1569.

43. Gaston BM, Carver J, Doctor A, Palmer LA. S-nitrosylation signaling in cell biology. Mol Interv 2003; 3: 253-263, doi: 10.1124/mi.3.5.253.

44. Choi YB, Tenneti L, Le DA, Ortiz J, Bai G, Chen HS, et al. Molecular basis of NMDA receptor-coupled ion channel modulation by S-nitrosylation. Nat Neurosci 2000; 3: 15-21, doi: $10.1038 / 71090$.

45. Lang RJ, Harvey JR, McPhee GJ, Klemm MF. Nitric oxide and thiol reagent modulation of $\mathrm{Ca}^{2+}$-activated $\mathrm{K}^{+}$(BKCa) channels in myocytes of the guinea-pig taenia caeci. $J$ Physiol 2000; 525 (Part 2): 363-376, doi: 10.1111/j.14697793.2000.00363.x.

46. Broillet MC, Firestein S. Direct activation of the olfactory cyclic nucleotide-gated channel through modification of sulfhydryl groups by NO compounds. Neuron 1996; 16: 377-385, doi: 10.1016/S0896-6273(00)80055-0.

47. Wenker IC, Benoit JP, Chen X, Liu H, Horner RL, Mulkey DK. Nitric oxide activates hypoglossal motoneurons by cGMP-dependent inhibition of TASK channels and cGMPindependent activation of $\mathrm{HCN}$ channels. J Neurophysiol 2012; 107: 1489-1499, doi: 10.1152/jn.00827.2011.

48. Jaffrey SR, Erdjument-Bromage H, Ferris CD, Tempst P, Snyder SH. Protein S-nitrosylation: a physiological signal for neuronal nitric oxide. Nat Cell Biol 2001; 3: 193-197, doi: $10.1038 / 35055104$.

49. Yasin S, Costa A, Trainer P, Windle R, Forsling ML, Grossman A. Nitric oxide modulates the release of vasopressin from rat hypothalamic explants. Endocrinology 1993; 133: 1466-1469, doi: 10.1210/en.133.3.1466.

50. Summy-Long JY, Bui V, Mantz S, Koehler E, Weisz J, Kadekaro M. Central inhibition of nitric oxide synthase preferentially augments release of oxytocin during dehydration. Neurosci Lett 1993; 152: 190-193, doi: 10.1016/03043940(93)90515-M.

51. Stern JE, Zhang W. Cellular sources, targets and actions of constitutive nitric oxide in the magnocellular neurosecretory system of the rat. J Physiol 2005; 562: 725-744, doi: 10.1113/jphysiol.2004.077735. 
52. da Silva MP, Ventura RR, Varanda WA. Hypertonicity increases NO production to modulate the firing rate of magnocellular neurons of the supraoptic nucleus of rats. Neuroscience 2013; 250: 70-79, doi: 10.1016/j.neuroscience. 2013.06.067.

53. Ueta Y, Levy A, Chowdrey HS, Lightman SL. Water deprivation in the rat induces nitric oxide synthase (NOS) gene expression in the hypothalamic paraventricular and supraoptic nuclei. Neurosci Res 1995; 23: 317-319, doi: 10.1016/0168-0102(95)00956-6.

54. Reis WL, Saad WA, Camargo LA, Elias LL, AntunesRodrigues J. Central nitrergic system regulation of neuroendocrine secretion, fluid intake and blood pressure induced by angiotensin-II. Behav Brain Funct 2010; 6: 64, doi: 10.1186/1744-9081-6-64.

55. Calka J, Block $\mathrm{CH}$. Angiotensin-(1-7) and nitric oxide synthase in the hypothalamo-neurohypophysial system. Brain Res Bull 1993; 30: 677-685, doi: 10.1016/03619230(93)90099-W.

56. Ota M, Crofton JT, Festavan GT, Share L. Evidence that nitric oxide can act centrally to stimulate vasopressin release. Neuroendocrinology 1993; 57: 955-959, doi: $10.1159 / 000126459$.

57. Rossi NF, Beierwaltes WH. Nitric oxide modulation of ET(B) receptor-induced vasopressin release by rat and mouse hypothalamo-neurohypophyseal explants. Am J Physiol Regul Integr Comp Physiol 2006; 290: R1208-R1215, doi: 10.1152/ajpregu.00701.2005.

58. Nicholson C. Diffusion from an injected volume of a substance in brain tissue with arbitrary volume fraction and tortuosity. Brain Res 1985; 333: 325-329, doi: 10.1016/ 0006-8993(85)91586-0.

59. Liu H, Terrell ML, Bui V, Summy-Long JY, Kadekaro M. Nitric oxide control of drinking, vasopressin and oxytocin release and blood pressure in dehydrated rats. Physiol Behav 1998; 63: 763-769, doi: 10.1016/S0031-9384(97)00528-3.

60. Kadekaro M, Summy-Long JY. Centrally produced nitric oxide and the regulation of body fluid and blood pressure homeostases. Clin Exp Pharmacol Physiol 2000; 27: 450459, doi: 10.1046/j.1440-1681.2000.03264.x.

61. Ventura RR, Gomes DA, Reis WL, Elias LL, Castro M, Valenca MM, et al. Nitrergic modulation of vasopressin, oxytocin and atrial natriuretic peptide secretion in response to sodium intake and hypertonic blood volume expansion. Braz J Med Biol Res 2002; 35: 1101-1109, doi: 10.1590/ S0100-879X2002000900011.

62. Serino R, Ueta $\mathrm{Y}$, Hanamiya M, Nomura M, Yamamoto $\mathrm{Y}$, Yamaguchi $\mathrm{KI}$, et al. Increased levels of hypothalamic neuronal nitric oxide synthase and vasopressin in saltloaded Dahl rat. Auton Neurosci 2001; 87: 225-235, doi: 10.1016/S1566-0702(00)00279-4.

63. Aguila FA, Oliveira-Pelegrin GR, Yao ST, Murphy D, Rocha MJ. Anteroventral third ventricle (AV3V) lesion affects hypothalamic neuronal nitric oxide synthase (nNOS) expression following water deprivation. Brain Res Bull 2011; 86: 239-245, doi: 10.1016/j.brainresbull.2011.07.020.

64. McKinley MJ, McAllen RM, Davern P, Giles ME, Penschow $J$, Sunn N, et al. The sensory circumventricular organs of the mammalian brain. Adv Anat Embryol Cell Biol 2003; 172: III-122, back, doi: 10.1007/978-3-642-55532-9.

65. Ferguson AV, Kasting NW. Angiotensin acts at the subfornical organ to increase plasma oxytocin concentrations in the rat. Regul Pept 1988; 23: 343-352, doi: 10.1016/ 0167-0115(88)90235-2.

66. Tanaka J, Saito H, Kaba H, Seto K. Subfornical organ neurons act to enhance the activity of paraventricular vasopressin neurons in response to intravenous angiotensin II. Neurosci Res 1987; 4: 424-427, doi: 10.1016/01680102(87)90008-3.

67. Okuya S, Inenaga K, Kaneko T, Yamashita H. Angiotensin II sensitive neurons in the supraoptic nucleus, subfornical organ and anteroventral third ventricle of rats in vitro. Brain Res 1987; 402: 58-67, doi: 10.1016/0006-8993(87)91047-X.

68. Jhamandas JH, Lind RW, Renaud LP. Angiotensin II may mediate excitatory neurotransmission from the subfornical organ to the hypothalamic supraoptic nucleus: an anatomical and electrophysiological study in the rat. Brain Res 1989; 487: 52-61, doi: 10.1016/0006-8993(89)90939-6.

69. Zhang L, Tong M, Xiao M, Li L, Ding J. Nitric oxide mediates feedback inhibition in angiotensin II-induced upregulation of vasopressin mRNA. Peptides 2009; 30: 913-917, doi: 10.1016/j.peptides.2009.01.024.

70. Wang G, Coleman CG, Glass MJ, Zhou P, Yu Q, Park L, et al. Angiotensin II type 2 receptor-coupled nitric oxide production modulates free radical availability and voltage-gated $\mathrm{Ca}^{2+}$ currents in NTS neurons. Am J Physiol Regul Integr Comp Physiol 2012; 302: R1076-R1083, doi: 10.1152/ajpregu. 00571.2011.

71. Coleman CG, Anrather J, ladecola C, Pickel VM. Angiotensin II type 2 receptors have a major somatodendritic distribution in vasopressin-containing neurons in the mouse hypothalamic paraventricular nucleus. Neuroscience 2009; 163: 129-142, doi: 10.1016/j.neuroscience.2009. 06.032 .

72. Zhu M, Gelband $\mathrm{CH}$, Moore JM, Posner P, Sumners C. Angiotensin II type 2 receptor stimulation of neuronal delayed-rectifier potassium current involves phospholipase A2 and arachidonic acid. J Neurosci 1998; 18: 679-686.

73. Yamaguchi K, Hama H, Watanabe K. Possible roles of prostaglandins in the anteroventral third ventricular region in the hyperosmolality-evoked vasopressin secretion of conscious rats. Exp Brain Res 1997; 113: 265-272, doi: 10.1007/BF02450324.

74. Yamaguchi K, Hama H, Watanabe K. Possible participation of prostaglandins generated in the anteroventral third ventricular region in the hypovolemia-induced vasopressin secretion of conscious rats. Eur J Endocrinol 1998; 138: 206-215, doi: 10.1530/eje.0.1380206.

75. Negro-Vilar A, Snyder GD, Falck JR, Manna S, Chacos N, Capdevila J. Involvement of eicosanoids in release of oxytocin and vasopressin from the neural lobe of the rat pituitary. Endocrinology 1985; 116: 2663-2668, doi: 10.1210/endo-116-6-2663.

76. Hetu PO, Riendeau D. Cyclo-oxygenase-2 contributes to constitutive prostanoid production in rat kidney and brain. Biochem J 2005; 391: 561-566, doi: 10.1042/BJ20050451.

77. Knigge U, Kjaer A, Kristoffersen U, Madsen K, Toftegaard $C$, Jorgensen $H$, et al. Histamine and prostaglandin interaction in regulation of oxytocin and vasopressin secretion. J Neuroendocrinol 2003; 15: 940-945, doi: 10.1046/j.1365-2826.2003.01079.x.

78. Salvemini D, Kim SF, Mollace V. Reciprocal regulation of 
the nitric oxide and cyclooxygenase pathway in pathophysiology: relevance and clinical implications. Am J Physiol Regul Integr Comp Physiol 2013; 304: R473-R487, doi: 10.1152/ajpregu.00355.2012.

79. Ueta Y, Levy A, Lightman SL. Gene expression in the supraoptic nucleus. Microsc Res Tech 2002; 56: 158-163, doi: 10.1002/jemt.10020.

80. Shibuya I, Setiadji SV, Ibrahim N, Harayama N, Maruyama $T$, Ueta $Y$, et al. Involvement of postsynaptic EP4 and presynaptic EP3 receptors in actions of prostaglandin E2 in rat supraoptic neurones. J Neuroendocrinol 2002; 14: 6472, doi: 10.1046/j.1365-2826.2002.00741.x.

81. Kadekaro M, Terrell ML, Liu H, Bui V, Summy-Long JY. Indomethacin prevents the L-NAME-induced increase in plasma levels of oxytocin in dehydrated rats. Brain Res 2000; 877: 371-373, doi: 10.1016/S0006-8993(00)02699-8.

82. Ozaki M, Shibuya I, Kabashima N, Isse T, Noguchi J, Ueta $Y$, et al. Preferential potentiation by nitric oxide of spontaneous inhibitory postsynaptic currents in rat supraoptic neurones. J Neuroendocrinol 2000; 12: 273-281, doi: 10.1046/j.1365-2826.2000.00448.x.

83. Kabashima N, Shibuya I, Ibrahim N, Ueta Y, Yamashita H. Inhibition of spontaneous EPSCs and IPSCs by presynaptic GABAB receptors on rat supraoptic magnocellular neurons.
J Physiol 1997; 504 (Part 1): 113-126, doi: 10.1111/j.14697793.1997.113bf.x.

84. Martinez-Ruiz A, Cadenas S, Lamas S. Nitric oxide signaling: classical, less classical, and nonclassical mechanisms. Free Radic Biol Med 2011; 51: 17-29, doi: 10.1016/j.freeradbiomed.2011.04.010.

85. Sharif Naeini R, Witty MF, Seguela P, Bourque CW. An $\mathrm{N}$-terminal variant of Trpv1 channel is required for osmosensory transduction. Nat Neurosci 2006; 9: 93-98, doi: 10.1038/nn1614.

86. Reis WL, Giusti-Paiva A, Ventura RR, Margatho LO, Gomes DA, Elias LL, et al. Central nitric oxide blocks vasopressin, oxytocin and atrial natriuretic peptide release and antidiuretic and natriuretic responses induced by central angiotensin II in conscious rats. Exp Physiol 2007; 92: 903-911, doi: 10.1113/expphysiol.2007.037911.

87. Cao L, Sun X, Shen E. Nitric oxide stimulates both the basal and reflex release of vasopressin in anesthetized rats. Neurosci Lett 1996; 221: 49-52, doi: 10.1016/S0304-3940 (96)13284-5.

88. Kadekaro M, Liu H, Terrell ML, Gestl S, Bui V, Summy-Long JY. Role of NO on vasopressin and oxytocin release and blood pressure responses during osmotic stimulation in rats. Am J Physiol 1997; 273: R1024-R1030. 